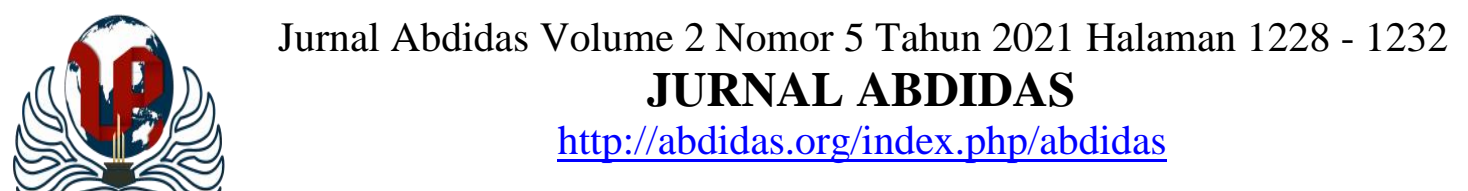

UNIVERSITAS

\title{
Pelatihan Penggunaan Aplikasi Zipgrade untuk Pemeriksaan Lembar Jawaban Siswa pada Bentuk Tes Multiple Choice
}

\author{
Sri Wahyuni ${ }^{1 \bowtie}$, Amalia Buntu ${ }^{2}$, Syech Zainal ${ }^{3}$, Moh. Sabran ${ }^{4}$ \\ Universitas Tadulako, Indonesia ${ }^{1,2,3,4}$ \\ E-mail : sri_wahyuniuntad18@yahoo.com ${ }^{1}$, amabuntu16@gmail.com² ${ }^{2}$ syechzainal67@gmail.com ${ }^{3}$, \\ sabran_bios@ rocketmail.com ${ }^{4}$
}

\begin{abstract}
Abstrak
Kegiatan ini bertujuan meningkatkan wawasan dan kemampuan calon mahasiswa PPL Program Studi Pendidikan Biologi dalam penggunaan aplikasi zipgrade untuk pemeriksaan lembar jawaban siswa. Hal itu dimaksudkan agar memudahkan calon mahasiswa PPL dalam memberikan evaluasi dan memeriksa hasil evaluasi tersebut. Untuk mencapai tujuan tersebut, maka perlu dilakukan pendekatan berupa pelatihan bagi calon mahasiswa PPL. Kegiatan pelatihan yang dilakukan ini bertujuan untuk memanfaatkan smartphone dan program aplikasinya yang disebut dengan zipgrade untuk mempermudah dan mempercepat proses pemeriksaan hasil dari bentuk penilaian tes multiple choice. Kegiatan pelatihan ini dihadiri oleh 15 peserta yaitu calon mahasiswa yang akan melaksanakan PPL di berbagai sekolah yang ada di Kota Palu. Aplikasi zipgrade dapat diunduh secara gratis di playstore. Materi yang diberikan pada kegiatan pelatihan ini mulai dari pengenalan software atau aplikasi pemeriksa lembar jawaban hingga cara pemanfaatan aplikasi tersebut. Dengan adanya kegiatan pelatihan ini maka diharapkan calon mahasiswa PPL telah mampu menggunakan aplikasi Zipgrade dan menerapkannya pada proses pembelajaran di sekolah.
\end{abstract}

Kata kunci: aplikasi zipgrade, pemeriksaan, lembar jawaban siswa, multiple choice

\begin{abstract}
This activity aims to increase the insight and ability of prospective PPL students of the Biology Education Study Program in using the zipgrade application to examine student answer sheets. This is intended to make it easier for prospective PPL students to provide evaluations and check the results of the evaluation. To achieve this goal, it is necessary to approach in the form of training for prospective PPL students. This training activity aims to utilize smartphones and their application program called zipgrade to simplify and speed up the process of checking the results of the multiple choice test assessment form. This training activity was attended by 15 participants, namely prospective students who will carry out PPL in various schools in Palu City. The zipgrade application can be downloaded for free on the playstore. The material provided in this training activity starts from the introduction of software or an answer sheet checking application to how to use the application. With this training activity, it is hoped that prospective PPL students will be able to use the Zipgrade application and apply it to the learning process at school.
\end{abstract}

Keywords: zipgrade application, examination, student answer sheet, multiple choice

Copyright (c) 2021 Sri Wahyuni, Amalia, Syech Zainal, Moh. Sabran

$\triangle$ Corresponding author

Address : Pendidikan Biologi FKIP UNTAD

ISSN 2721- 9224 (Media Cetak)

Email : sri_wahyuniuntad18@yahoo.com

ISSN 2721- 9216 (Media Online)

DOI : https://doi.org/10.31004/abdidas.v2i5.453 
1229 Pelatihan Penggunaan Aplikasi Zipgrade untuk Pemeriksaan Lembar Jawaban Siswa pada Bentuk Tes Multiple Choice - Sri Wahyuni, Amalia, Syech Zainal, Moh. Sabran

DOI: https://doi.org/10.31004/abdidas.v2i5.453

\section{PENDAHULUAN}

Saat ini, perkembangan teknologi komunikasi dan informasi maju dengan sangat pesat. Perkembangan tersebut tidak bisa dihindari pengaruhnya terhadap dunia pendidikan. Berbagai inovasi dan pembaharuan dalam dunia pendidikan telah memberi dampak yang besar contohnya pemanfaatan laptop dan smartphone yang memudahkan siswa untuk mengakses materi pembelajaran, dan memudahkan siswa untuk belajar. Teknologi dapat meningkatkan kualitas dan jangkauan apabila digunakan secara bijak untuk pendidikan dan latihan, dan mempunyai arti yang sangat penting bagi kesejahteraan (Budiman, 2017).

Teknologi lain yang paling populer dimanfaatkan saat ini adalah smartphone. Kebanyakan orang telah memiliki smartphone karena telah menjadi kebutuhan dasar bagi mereka. Alasan pemanfaatan teknologi smartphone ini yaitu memiliki kelebihan karena mudah dibawa kemana-mana. Namun, kekurangannya adalah pemanfaatan teknologi smartphone masih kurang digunakan dalam proses pembelajaran. Faktanya, hal tersebut sangatlah penting demi meningkatkan mutu dan kualitas pendidikan. Padahal guru dan calon guru telah mahir menggunakan smartphone, dalam hal ini mengakses internet.

Hampir semua sekolah yang ada di Kota Palu umumnya telah melaksanakan proses pembelajaran dengan menggunakan laptop dan infocus. Bahkan, ada sekolah yang memiliki laboratorium komputer yang biasanya digunakan untuk melaksanakan UN berbasis komputer. Ada banyak program atau aplikasi dalam smartphone yang bisa dimanfaatkan dalam proses pembelajaran, salah satunya bisa digunakan dalam pelaksanaan evaluasi pembelajaran. Namun, kurangnya pengetahuan calon guru, khususnya calon mahasiswa PPL yang akan melaksanakan praktek mengajar di sekolah mengakibatkan tidak tercapainya pemanfaatan teknologi dalam proses pembelajaran. Olehnya itu, perlu adanya suatu upaya kegiatan untuk memecahkan permasalahan tersebut. Kegiatan tersebut berupa pelatihan kepada calon mahasiswa PPL sebagai bekal dalam pengembangan instrumen evaluasi pembelajaran dengan memanfaatkan berbagai aplikasi zipgrade sehingga evaluasi pembelajaran menjadi efektif dan efisien.

\section{METODE}

Kegiatan pelatihan penggunaan aplikasi zipgrade dilaksanakan secara virtual yaitu melalui zoom cloud meeting pada bulan Mei 2021. Kelompok sasaran dalam kegiatan pelatihan ini yaitu mahasiswa PPL program studi pendidikan biologi sebanyak 15 orang yang mewakili sebagian sekolah yang ada di Kota Palu sebagai tempat pelaksanaan PPL.

Pelaksanaan kegiatan pelatihan ini menggunakan metode pelatihan dengan langkahlangkah berikut: a) Penjelasan materi terkait aplikasi zipgrade dan penjelasan langkah-langkah penginstalan aplikasi tersebut secara virtual (melalui zoom), b) setiap calon mahasiswa PPL diharapkan menyiapkan hasil tes evaluasi sebagai langkah awal dalam mensimulasikan aplikasi zipgrade, c) setelah aplikasi masing-masing diinstal oleh mahasiswa, maka langkah selanjutnya 
1230 Pelatihan Penggunaan Aplikasi Zipgrade untuk Pemeriksaan Lembar Jawaban Siswa pada Bentuk Tes Multiple Choice - Sri Wahyuni, Amalia, Syech Zainal, Moh. Sabran

DOI: https://doi.org/10.31004/abdidas.v2i5.453

yaitu membuka program aplikasi zipgrade di smartphone kemudian memasukkan kunci jawaban dengan cara memilih alternatif jawaban yang tersedia, d) langkah lain yang bisa dilakukan yaitu dengan menscan kunci jawaban yang telah dibuat pada format lembar jawaban yang telah disediakan, e) lembar jawaban yang telah diisi oleh siswa disusun secara rapi dan discan satu persatu, f) skor hasil penilaian secara otomatis akan ditampilkan dan disimpan pada saat proses scan dimulai, g) data yang tersimpan di smartphone dapat digunakan untuk melihat jawaban setiap siswa, tingkat kesukaran soal, daya pembeda alternatif jawaban, h) langkah selanjutnya yaitu setiap calon mahasiswa PPL dilatih cara membaca hasil/skor yang secara otomatis akan terekam di smartphone, i) setelah selesai, maka langkah selanjutnya yaitu skor tersebut dapat dicetak dan dikirimkan melalui beberapa media sosial, misalnya wa dan e-mail.

\section{HASIL DAN PEMBAHASAN}

Kegiatan pelatihan ini terlaksana dengan baik dan lancar. Pelaksanaan kegiatan dimulai dengan tahapan sebagai berikut: Persiapan, tahapan persiapan kegiatan ini membutuhkan waktu yang sangat lama disebabkan oleh masa pandemi Covid-19. Persiapan kegiatan tersebut meliputi: a) menentukan lokasi (mitra pengabdian masyarakat) dan menentukan calon mahasiswa PPL yang menjadi sasaran dalam pelaksanaan kegiatan pelatihan ini, b) melakukan koordinasi bersama dosen-dosen prodi pendidikan biologi yang tergabung dalam tim pengabdian, c) melakukan koordinasi dengan calon mahasiswa
PPL tentang pelatihan penggunaan aplikasi zipgrade yang akan mempermudah mahasiswa tersebut dalam memeriksa lembar jawaban siswa, d) mempersiapkan materi pelatihan yang akan ditayangkan pada saat pemaparan materi melalui zoom cloud meeting.

Pelaksanaan, dalam tahapan kegiatan pelaksanaan pelatihan ini berjalan sesuai dengan waktu yang telah disepakati oleh tim pengabdi dan calon mahasiswa PPL. Tahapan kegiatan tersebut diantaranya: a) pemaparan dan penjelasan materi terkait aplikasi zipgrade. Tahapan kegiatan pertama ini dilakukan bertujuan untuk memberi pemahaman kepada calon mahasiswa PPL tentang aplikasi zipgrade serta kelebihan dan kekurangannya. Hal ini dimaksudkan agar mahasiswa dapat memahami bahwa setiap aplikasi, baik yang ada dalam smartphone maupun komputer memiliki kelebihan dan kekurangannya masing-masing, b) penjelasan langkah-langkah penginstalan aplikasi dan pengoperasian aplikasi tersebut. Kegiatan ini bertujuan untuk menjelaskan kepada mahasiswa cara menginstall aplikasi zipgrade dan cara menggunakan aplikasi tersebut. Penggunaan aplikasi tersebut sangat mudah, namun perlu teknik yang bagus dalam pengoperasiannya, khususnya pada saat menscan lembar jawaban, c) pengarahan kepada calon mahasiswa PPL dalam mengunduh dan menginstall aplikasi. Tahapan kegiatan ini bertujuan untuk menuntun mahasiswa dalam mengunduh dan menginstall aplikasi zipgrade di smartphone masing-masing, d) melakukan simulasi penggunaan aplikasi zipgrade terhadap calon mahasiswa PPL. Kegiatan simulasi 
1231 Pelatihan Penggunaan Aplikasi Zipgrade untuk Pemeriksaan Lembar Jawaban Siswa pada Bentuk Tes Multiple Choice - Sri Wahyuni, Amalia, Syech Zainal, Moh. Sabran

DOI: https://doi.org/10.31004/abdidas.v2i5.453

dilakukan bertujuan untuk mempermudah dan memperlancar mahasiswa dalam menggunakan aplikasi zipgrade sehingga pada saat memeriksa lembar jawaban siswa, mahasiswa PPL dapat lebih mudah dan lebih cepat, e) melakukan evaluasi terhadap hasil simulasi yang telah dilakukan oleh para mahasiswa PPL. Kegiatan evaluasi sangat perlu dilakukan dalam kegiatan pelatihan ini.

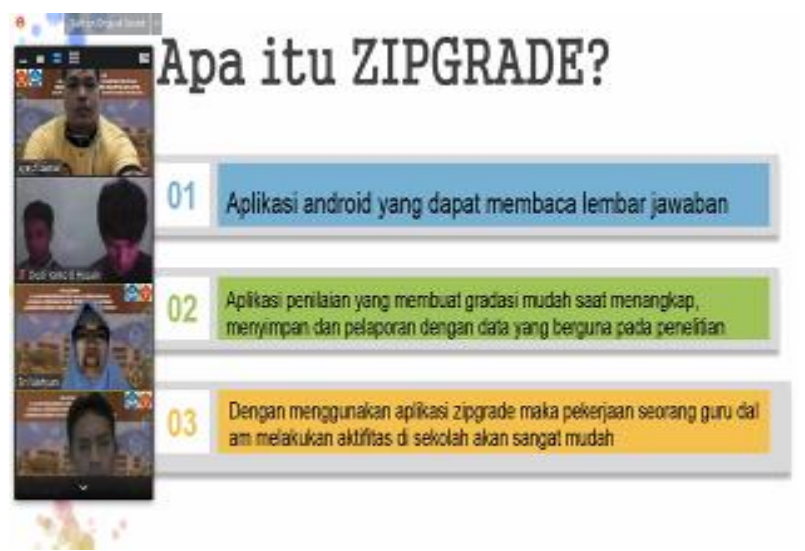

Gambar 1. Pengenalan Aplikasi Zipgrade

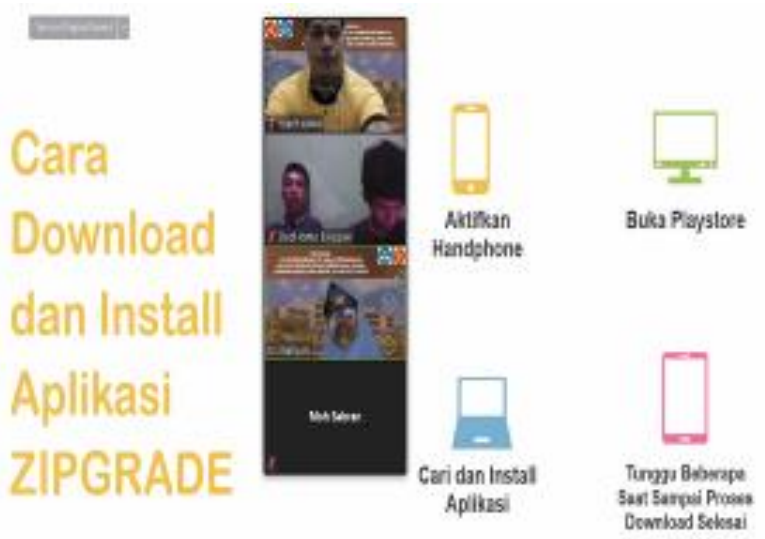

Gambar 2. Cara Download Aplikasi Zipgrade

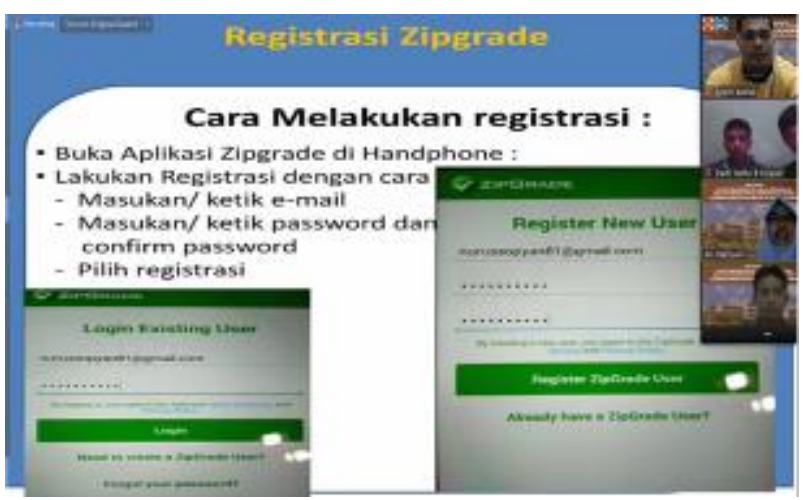

Gambar 3. Cara Resgisterasi Aplikasi Zipgrade

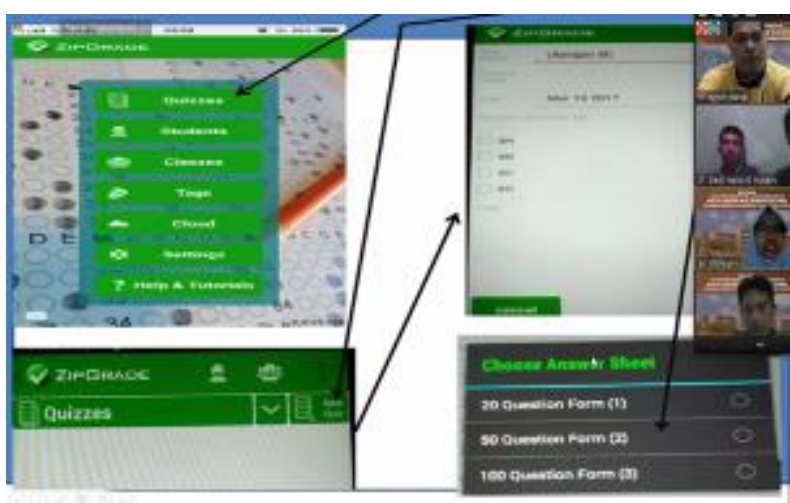

Gambar 4. Cara Menggunakan Aplikasi Zipgrade

Hasil dari kegiatan pelatihan ini mencakup beberapa komponen, yaitu: a) tercapainya target tujuan kegiatan pelatihan, b) tercapainya jumlah peserta pelatihan, serta c) tercapainya materi yang disampaikan dan kemampuan peserta dalam memahami materi tersebut. Target tujuan pelatihan telah tercapai yaitu dapat menambah wawasan dan kemampuan calon mahasiswa PPL dalam menggunakan aplikasi zipgrade. Hala ini sejalan dengan Prasmono (2011) bahwa Pemanfaatan teknologi di bidang pendidikan memberikan peluang yang besar kepada calon pendidik dan pendidik dalam mengembangkan model pembelajaran yang menarik dan bersifat interaktif. Target jumlah peserta pelatihan berjumlah 15 
1232 Pelatihan Penggunaan Aplikasi Zipgrade untuk Pemeriksaan Lembar Jawaban Siswa pada Bentuk Tes Multiple Choice - Sri Wahyuni, Amalia, Syech Zainal, Moh. Sabran

DOI: https://doi.org/10.31004/abdidas.v2i5.453

orang mahasiswa PPL yang tersebar di beberapa sekolah yang ada di Kota Palu. Dari jumlah peserta pelatihan tersebut dapat menunjukkan bahwa kegiatan pelatihan ini dapat dikatakan telah berhasil. Selanjutnya yaitu tercapainya materi yang disampaikan oleh tim pengabdi. Materi pelatihan ini telah disampaikan dan dijelaskan secara rinci, dimulai dari penjelasan aplikasi zipgrade bahwa zipgrade merupakan aplikasi untuk penilaian berbentuk pilihan ganda dengan menggunakan android untuk menscan lembar jawaban peserta penilaian. Jadi, dengan aplikasi ini seorang penilai tidak perlu lagi menggunakan alat scanner khusus seperti scantron ataupun lainnya. Dengan zipgrade penilaian dapat langsung mendapatkan umpan balik dan dapat tahu skor setelah mengikuti penilaian (Sihwidi, 2018). Menurut Fitria (2018) zipgrade sebagai aplikasi penilaian dilengkapi kemampuan-kemampuan dan fitur yang cukup dan umum diharapkan dari sebuah penilaian.

\section{SIMPULAN}

Berdasarkan hasil pelaksanaan kegiatan pelatihan ini, dapat disimpulkan bahwa kegiatan pelatihan ini mampu menambah wawasan dan kemampuan calon mahasiswa PPL dalam menggunakan aplikasi zipgrade sehingga dapat mempermudah mahasiswa dalam memeriksa lembar jawaban siswa setelah diberikan evaluasi.

\section{UCAPAN TERIMA KASIH}

Ucapan terima kasih kami sampaikan kepada pimpinan Universitas, Lembaga Penelitian dan Pengabdian Masyarakat, Dekan FKIP Universitas Tadulako, serta Mitra yang telah memberikan izin administratif sehingga pengabdian ini dapat terlaksana.

\section{DAFTAR PUSTAKA}

Budiman, H. (2017). Peran Teknologi Informasi Dan Komunikasi Dalam Pendidikan. Jurnal Pendidikan Islam. Volume 8 No. I. P.Issn: 20869118. E-Issn: 2528-2476.

Fitria, R. (2018). Penilaian Semudah Selfie Dengan Zipgrade. Solok: Penerbit Igi Solok, Indonesia.

Prasmono, A. (2011). Pengaruh Penggunaan Media Pembelajaran Komputer Multimedia Dan Digital Video Disc Terhadap Prestasi Belajar Listening Ditinjau Dari Motivasi Belajar Siswa Sekolah Menengah Pertama Di Kabupaten Wonogiri. Digital Library Upt. Perpustakaan Universitas Sebelas Maret. Solo.

Sihwidi, J. (2018). Menilai Hasil Belajar Cepat, Tepat, Dan Akurat Dengan Plickerszipgrade. Yogyakarta: Penerbit Deepublish. 